Original Research Article

\title{
Survey on the traditional medicinal plant species used to cure diabetes
}

Lal, Sanjeev ${ }^{1}$; Dhingra, Gulshan Kumar ${ }^{2}$ and Kaur, Rupinder ${ }^{3}$

${ }^{1}$ Department of Botany, Govt. P.G. College Kotdwar (Garhwal), Uttarakhand, India

${ }^{2}$ Department of Botany, Govt. P.G. College Rishikesh, Uttarakhand, India

Corresponding Author: gulshan_k_dhingra@yahoo.co.in

\section{A R T I C L E I N F O}

Received: 20 January 2018 | Accepted: 22 April 2018 | Published Online: 15 August 2018

DOI: $10.31786 / 09756272.18 .9 .1 .104$

EOI: $10.11208 /$ essence.18.9.1.104

Article is an Open Access Publication.

This work is licensed under Attribution-Non Commercial 4.0 International

(https://creativecommons.org/licenses/by/4.0/)

CThe Authors (2018). Publishing Rights @ MANU-ICMANU \& ESSENCE-IJERC.

\section{A B S T R A C T}

The present study deals with the survey on the antidiabetic plant species with discussed to local people, which regulate the blood sugar level. Diabetes or Madhumeha is a disease in which there is an improper functioning of insulin and increase the sugar level in the blood. Diabetes may cause heart problem, kidney failure, blurred vision if not treated timely. Diabetes mellitus is increasing alarmingly worldwide and is defined as the abnormal glucose tolerance, which affects pancreatic beta-cells functions and sensitivity leading to the development of diabetes and its related complications. It is a chronic disorder of carbohydrate, fat and protein metabolism characterized by increased fasting and post prandial blood sugar level and an increased risk of vascular complications. For this problem the different plant parts such as root, stem, leaf, flower, seeds, fruits and their crude extracts that have been used in the Indian traditional system of medicine and have clinical anti-diabetic activity. In the present investigation we have conducted an ethnobotanical survey to collect information about the use of traditional medicinal plants for diabetes treatment. Our survey has reported 24 numbers of medicinal plants belonging to different families. Family Cucubritaceae was found to be of high frequency in terms of its use with a maximum of 3 species.

\section{K E Y W O R D S}

Diabetes mellitus | Antidiabetic plants | Pancreatic beta cells | Hyperglycemia | Hypoglycemic effect | Insulin | Drug interaction | Herbal medicine | Traditional medicine.

\section{I T A T I O N}

Lal, Sanjeev; Dhingra, Gulshan Kumar and Kaur, Rupinder (2018): Survey on the traditional medicinal plant species used to cure diabetes. ESSENCE Int. J. Env. Rehab. Conserv. IX (1): 23-33. 


\section{Introduction}

Diabetes mellitus is one of the most prevalent chronic diseases throughout the world, which leads to various complications on long standing. Treatment with oral hypoglycemic drugs ends with numerous side effects. The potency of herbal medicine is significant and they have negligible side effects than existing synthetic anti-diabetic drugs. The plant species have proved their efficacy in reducing blood glucose levels so they are the best alternative for the treatment of diabetes mellitus. Recently, herbal products have started gaining importance as an alternative and complementary medicine to treat diabetic mellitus. According to the World Health Organization (1980) expert committee on diabetes, which recommends that traditional methods of management of diabetes should be further investigated.

Diabetes mellitus is a debilitating and often lifethreatening disease with increasing incidence in rural populations throughout the world. A scientific investigation of traditional herbal remedies for diabetes may provide valuable leads for the development of alternative drugs and therapeutic strategies. Alternatives are clearly needed because of the inability of current therapies to control all of the pathological aspects of diabetes and the high cost and poor availability of current therapies for many rural populations, particularly in developing countries. Prolonged persistence of elevated blood glucose level consequently caused a series of complications such as nephropathy, retinopathy and cardiomyopathy. Currently available synthetic drugs for treating this disease are found to be associated with many adverse effects.

The use of herbal species for medicinal benefits has played an important role in nearly every culture on earth and for many years, the search for anti-diabetic agents will continue to focus on plants and other natural resources. The use of plants in medicine is an age-long practice in various parts of the globe for both preventive and curative purposes. Several warnings have been issued over lack of quality control, scientific evidence for the efficacy and potential adverse effects of herbal remedies including hepatotoxicity, nephrotoxicity, cardiotoxicity and reproductive toxicity among others. Despite all of these, reliance on herbs as medicine for the management of diabetes mellitus is still much practiced by a large proportion of the world population, because they are readily available and affordable with perceived reduced toxicity. Easy availability, raw consumption, least side effects and low cost makes the herbal preparations the king of all available therapies. Diabetes and herbs have got a long relation from the past. Thus, plants are a potential source of anti-diabetic drugs which can be proved by the ethnobotanical information reports about 800 plants that may possess anti-diabetic potential.

Diabetes mellitus is one of the common metabolic disorders acquiring around $2.8 \%$ of the world's population and is anticipated to cross $5.4 \%$ by the year 2025. The antidiabetic activity of medicinal plants is attributed to the presence of polyphenols, flavonoids, terpenoids, coumarins and other constituents which show reduction in blood glucose levels. The evaluation of traditional medicinal plants, which are considered to be excellent candidates for oral diabetic therapy, has been recommended by the World Health Organization (WHO) as they are effective, non-toxic and with less or no side effects as were noted by World Health Organization (1980). However, some herbal extracts have been confirmed for hypoglycemic effects in human. Acacia arabica belonging to family Leguminosae is commonly known as Babbula in Sanskrit and Senegal in English. The ethno medicinal survey suggests that the plant $A$. arabica has diverse medicinal uses. The gum is used in diabetes. A. arabica has been proven to be a good hypolipidemic, hypoglycemic and antioxidant agent as was noted by Hegazy et al., (2013). The present work represents the profile of medicinal plants in the Doon valley of Shastradhara region which commonly used and proven to be effective anti-diabetic drugs. The profile of antidiabetic plants described its scientific name, family, common name, plant part used and its activity against diabetes. 


\section{Material and Methods}

The present investigation was a result of field surveys on the antidiabetic plants. The collected plants were identified with the help of recent and relevant floras such as Herbaceous Flora of Dehradun (Babu C. R., 1977) and forest flora of Dehradun, Saharanpur (Kanji Lal, 1928). Information on the medicinal properties and qualities of various plant species were collected through personal interview with the local inhabitants. Usually the information collected from the local Vaidya's or medicinal practitioners however; occasionally the information was also recovered by housewives, rural old folk and grazers of long experience.

\section{Study Area}

Study site is located in Doon valley of Shastradhara region (Uttarakhand) which is bound by lesser Himalayas in north and younger Siwaliks in the south and is limited by river Ganga and Yamuna in east and west respectively. It lies between longitude $77035^{\prime}$ 'to $78024^{\prime}$ 'east and latitude $29055^{\prime}$ and $30030^{\prime}$ 'north and covers an area of more than 2000 sq. km. Doon valley is situated on the North east corner of Uttaranchal between 780.5' east longitude and 300.24' North latitude. The present study was conducted during the year 2016 in Sahastradhara region and adjacent area. Present study

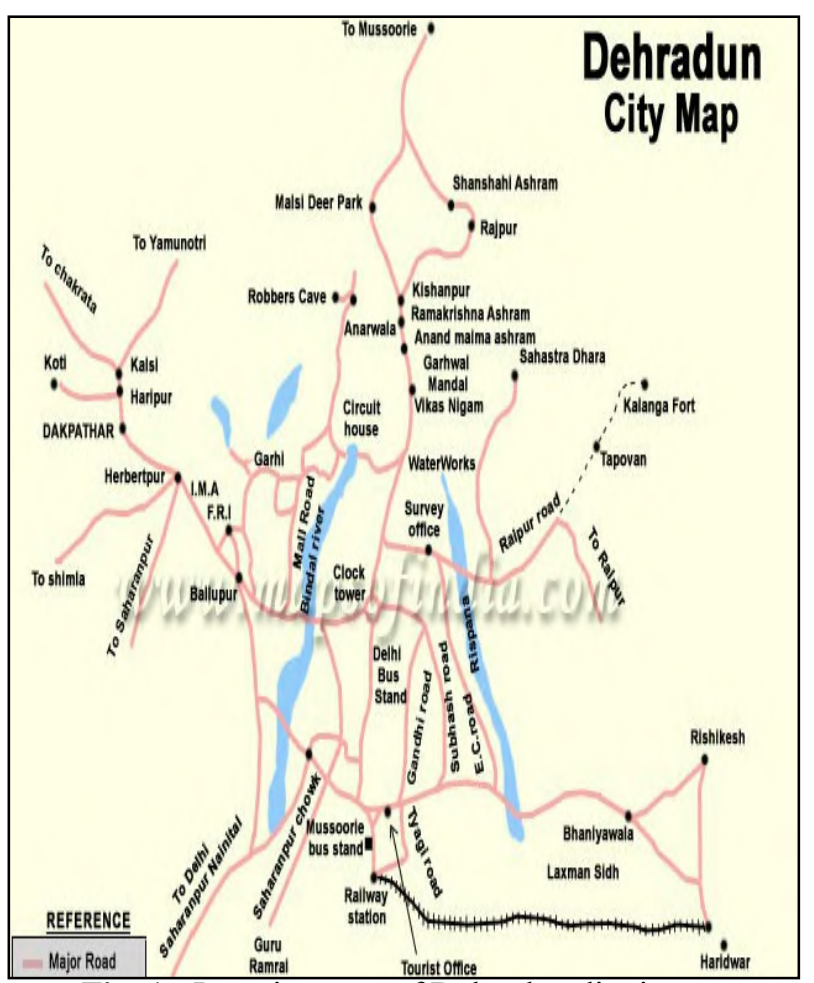

Fig. 1: Location map of Dehradun district based inventory on field level information Sahastradhara region of Dehradun. Sahastradhara region and adjoining area of Nagal Hatnala and some Catchment areas of Doon valley where we find out medicinal plants for our proposed work. In that region different types of medicinal floral diversity which show biodiversity variability so we were choose that area for our proposed work. While conducting the surveys on biodiversity including medicinal plants of the above regions, information was also gathered from local inhabitants about the medicinal properties of the some plants.

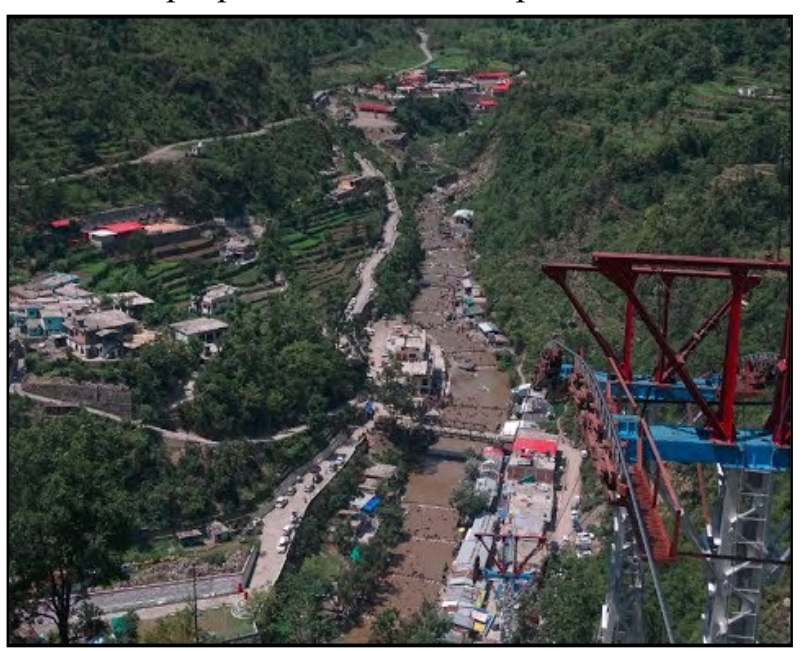

Fig. 2: Location map showing study site (Sahastradhara)

\section{Objectives of present work}

Following objectives were selected for the proposed work

1. Extensive survey and inventory with in study area of Sahastradhara, Doon Valley.

2. Literature collection with the help of libraries of College campus, F.R.I and B.S.I.

3. The different medicinal plant species with botanical name, local name and its family.

4. Find out how the local people use the plants and plant parts for the treating the various disease.

5. Find out such plants which are over exploited and concluding remark and suggest strategy for the conservation and management of medicinal floral vegetation.

6. The last not least step involves the analysis of different plant parts prone to specified diseases. The different plant parts which have been analyzed for the different medicinal prop- 
against different diseases includes:

- Root.

- Stem.

- Leaves.

- Flower.

- Bark.

- Seed

- Tube

\section{Observation and Results}

A total of 24 medicinal plant species belonging to different families were found to be used by the local people of the area surveyed under study for the treatment of diabetes. Almost all the plant/ plant-extracts were found to be prepared in aqueous solution and were consumed during the early hours of the day in empty stomach. Plant parts used more frequently such as bark, leaf, tuber, fruits, seed, stem, roots etc. used for the treatment of diabetes with their common name, botanical name and family used to cure diabetes are discussed below:

1. Allium cepa belonging to family Amaryllidaceae commonly known as Pyaz. Ethno medicinal survey and also experimentally it has been documented to possess antidiabetic potential. When diabetic patients were given single oral dose of 50 $\mathrm{g}$ of onion juice, it significantly controlled postprandial glucose levels. Fig. 1.

2. Acacia arabica belonging to family Leguminosae commonly known as Babbula in Sanskrit. The ethno medicinal survey suggests that $A$. arabica has diverse medicinal uses. The gum is used in diabetes. It has been proven to be a good hypolipidemic, hypoglycemic and antioxidant agent.

Fig. 2

3. Aegle marmelos belonging to family Rutaceae, commonly known as Shreephal in Sanskrit. It has a lot of synonyms in English like Holyfruit tree Bengal quince, Wood apple and Stone Apple. The trifoliate leaves of Bili emerge on the Hindu God Soned the most popular medicinal species with hypoglycemic effective and trifoliate leaves also represent the holy trinity of Brahma, Vishnu and Shiva. Leaf powder with cow's milk is taken orally/extracted juice mixed with a black pepper is taken orally with water daily for about one month. Fig. 3.

4. Azadirachta indica is commonly known as Neem belonging to family Meliaceae. The biological activities of the Neem components, pharmacological actions of neem extract of leaves significantly decrease blood sugar level. Leaf extracts significantly decreased blood sugar level. Fig. 4.

5. Brassica juncea is commonly known as brown mustard and its family is Brassicaceae. The oral administration of aqueous seed extract of $B$. juncea has a beneficial effect on diabetes. Powdered seeds mixed with lime juice are given regularly for about 15 days to cure diabetes. Fig. 5 .

6. Cajanus cajan, locally known as Tuar, belonging to family Fabaceae, is traditionally used in the treatment of diabetes mellitus. The glucose tolerance enhancing activity of aqueous leaf and stem extract has been using in diabetes and cooked seeds are taken as food. Fig. 6 .

7. Momordica charantia belongs to the family Cucurbitaceae, it is a slender, climbing annual vine commonly known as "bitter gourd" and "karela" grows in tropical regions. It is a very common folk remedy for diabetes. Extract of fruit pulp, seed, leaves and whole plant has shown hypoglycemic effect in various animal models. Oral administration of the fruit juice or seed powder causes a reduction in fasting blood glucose and improves glucose tolerance in normal and diabetic animals and in humans. Fig. 7.

8. Musa sapientum commonly known as Banana in English, Kela in Hindi belongs to the family Musaceae. Various parts of this plant are used for different medicinal purposes including diabetes. Stem extract reduces diabetes. Fig. 8 .

9. Punica granatum belongs to the family Punicaceae. The flowers of the plant Punica granatum are used as anti-diabetic in Unani medicine called Gulnarfarsi. Fruits used to treat diabetes. Fig. 9.

10. Syzigium cumini, commonly known as Jamun in Hindi and Black Berry in English and belongs to family Myrtaceae. It is used for the treatment of diabetes mellitus. Seed powder used and reduces blood sugar/diabetes. Fig. 10. 
11. Trigonella foenumgraceum commonly known as Methi is a well-known hypoglycemic agent used in traditional Indian medicines. Various extracts of different parts like fibers, proteins and saponins isolated from the seeds and found to possess significant hypoglycemic activity. Fig. 11.

12. Vinca rosea, belongs to family Apocynaceae, is found throughout India in wetlands and it is also cultivated. It is commonly known as Madagascar periwinkle, rosy periwinkle and "old maid". Oral administration of the extract of $V$. rosea leaves shows a significant dose-dependent reduction in blood sugar. Fig. 12.

13. Allium sativum, a member of the Liliaceae family. Its preparations have been widely recognized as agent for prevention and treatment of diabetes. Leaf and bulb taken orally to treat diabetes. Fig. 13.

14. Aloe vera or Aloe barbadensis (Ghrita kumari) belongs to the family Liliaceae. Aloe has a long history as a multipurpose folk remedy. Aloe vera gel is the leaf pulp or mucilage, aloe latex, commonly referred to as "aloe juice," is a bitter yellow exudate from the pericyclic tubules just beneath the outer skin of the leaves. The action of Aloe vera and its bitter principle is through stimulation of synthesis and/or release of insulin from pancreatic beta cells. Oral administration of Aloe vera might be effective in reducing blood glucose in diabetic patients.

15. Mangifera indica belongs to family Anacardiaceae, it is a well-known perennial tree commonly known as Mango. Seed and leaves are used for curing of diabetes. Dry kernel powder with cow's milk is taken till care.Dried and crushed leaves of mango (1 spoon) with a glass of water should be taken every day. This is one of the useful home remedies for diabetes and good natural cure for diabetes.

16. Ocimum sanctum is commonly known as Holy basil (Tulsi). Since ancient times, this plant is known for its medicinal properties. The aqueous extract of leaves of Ocimum sanctum showed the significant reduction in blood sugar level. Significant reduction in fasting blood glucose, total cholesterol, triglyceride and total lipid indicates the hypoglycemic effects of Tulsi in diabetic agent. Leaf powder is taken orally with honey.

17. Carica papya is commonly known as papaya, which belongs to the family Caricaceae. Papaya (Carica papaya) are boiled and made into a paste and given with a pinch of common salt and jeera powder for six months to cure diabetes.

18. Zingiber officinalis is commonly known as Adark belonging to family Zingiberaceae. Extract of rhizome (decoction) if consumed regularly it shows a control in blood sugar level.

19. Withania somnifera commonly known as Ashwagandha belonging to family Solanaceae. Leaf juice is useful for the treatment of diabetes.

20. Hibiscuss rosasinensis commonly known as Gurhal belonging to family Malvaceae. Its flower has antidiabetic property. One tea spoon powder of flower mixed with pepper is given once in the morning for about 10 days or more.

21. Emblica officinalis belongs to family Euphorbiaceae commonly known as Amla. One spoon of juice obtained from squeezed leaves is taken in the morning on an empty stomach. Fruits are chewed and taken as much as possible, dried fruits are soaked in water and the water is taken orally with the fruit.

22. Psidium guajava belongs to family Myrataceae commonly known as Amrood or Guava. Its decoction made from leaf and root is consumed regularly.

23. Ricinus communis belongs to family Euphorbiaceae, commonly known as Castor bean.Water extract of the plant is given twice daily, seeds powder is taken with milk.

24. Terminalia chebula belongs to family Combretaceae, commonly known as Harad. Fresh fruits are also dried when available and when not available, dried fruits are soaked in water overnight followed by drinking the water in the morning.

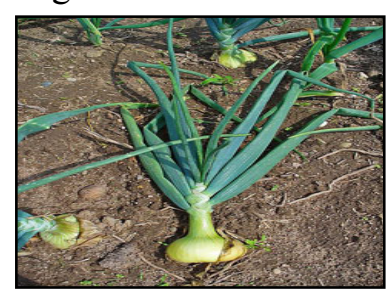

Fig. 1: Allium cepa

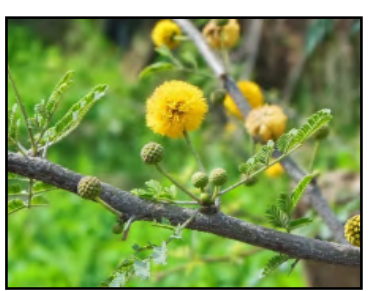

Fig. 2: Acacia Arabica 
ESSENCE_-IJERC | Sanjeev et al. (2018) | IX (1): 23-33

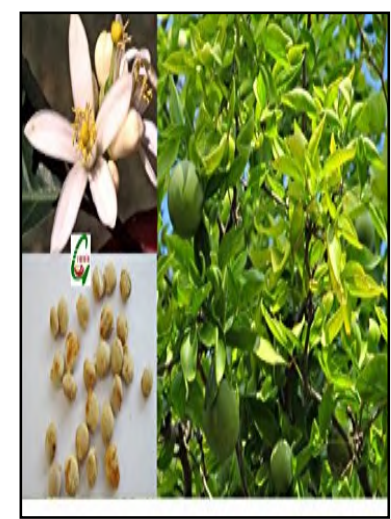

Fig. 3: Aegle marmelos

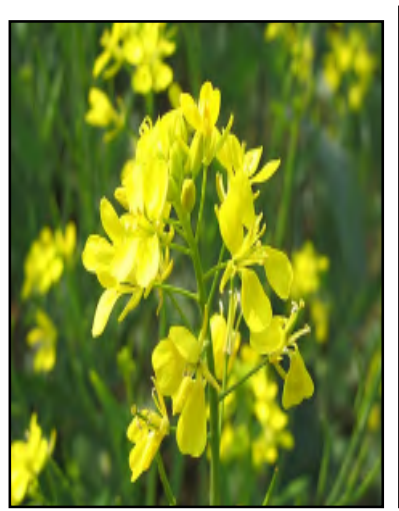

Fig. 5: Brassica juncea

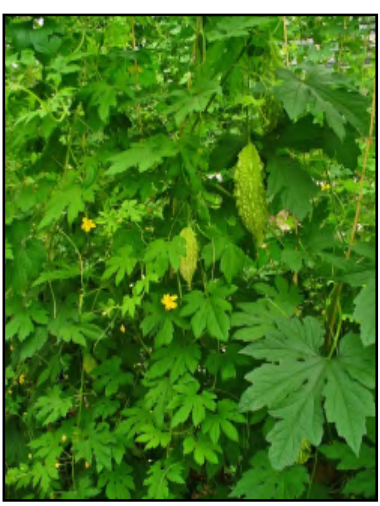

Fig. 7: Momordica charantia

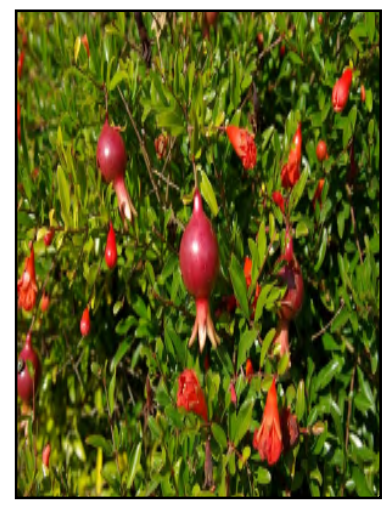

Fig. 9: Punica gratum

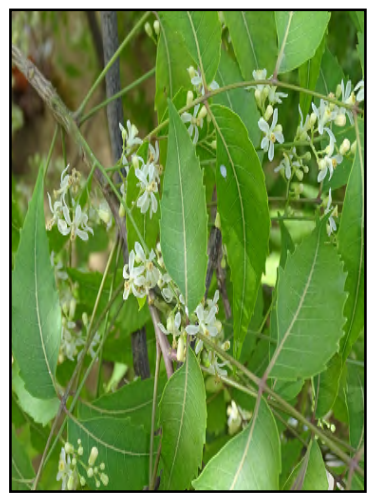

Fig. 4: Azadirachta indica

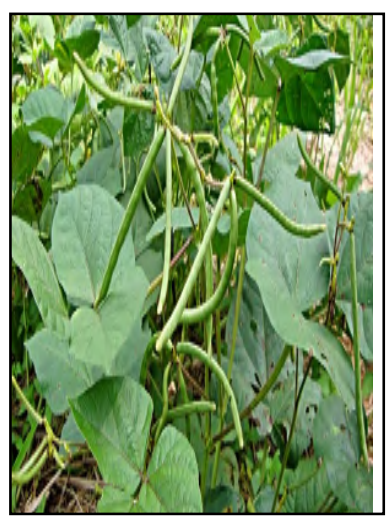

Fig. 6: Cajanus cajan

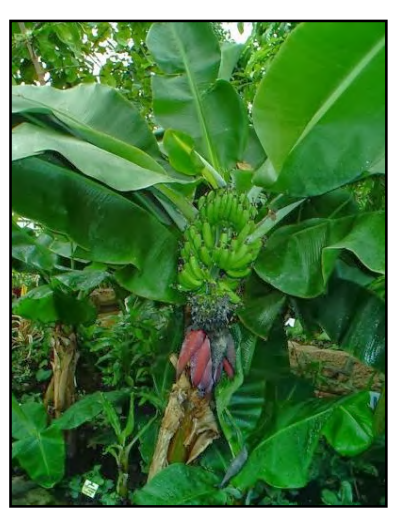

Fig. 8: Musa sapientum

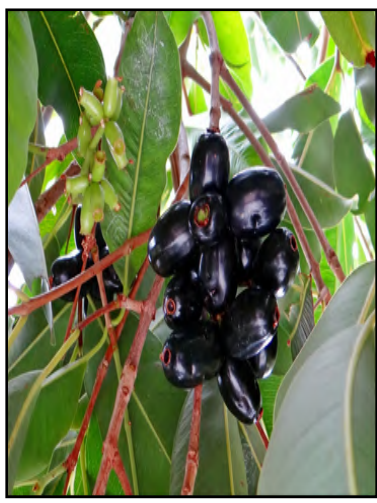

Fig. 10: Syzigium cumini
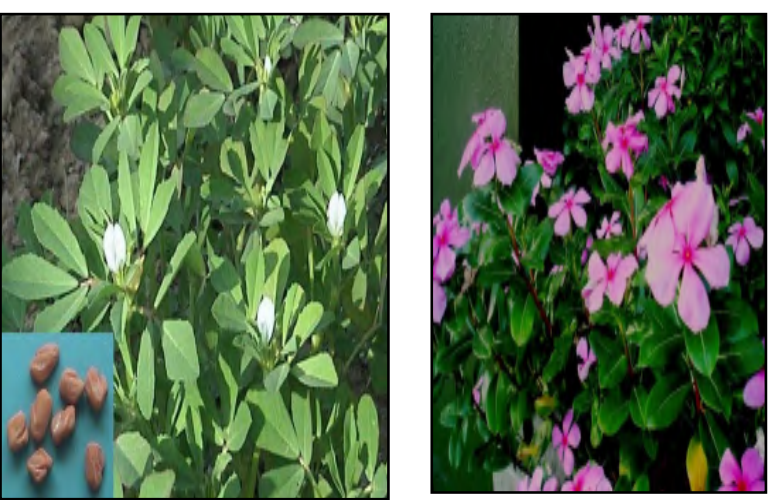

Fig. 11: Trigonella foenum-graecum

Fig. 12: Vicna

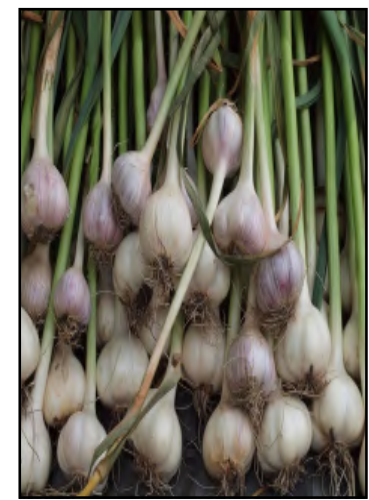

Fig. 13: Allium sativum

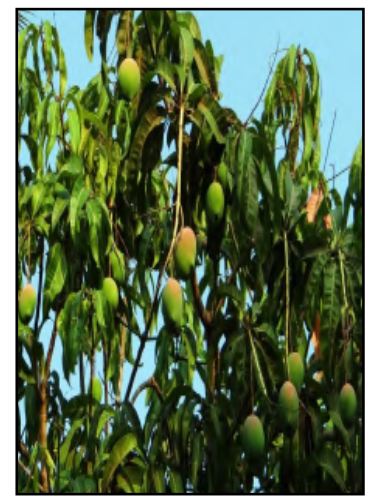

Fig. 15: Mangifera indica

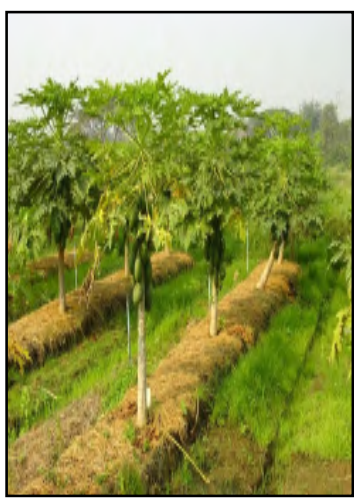

Fig. 17: Carica papaya

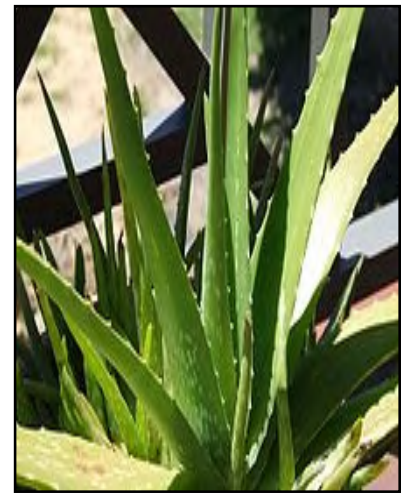

Fig. 14: Aloe vera

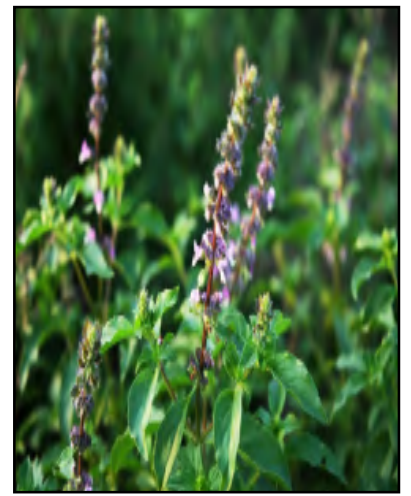

Fig. 16: Ocimum

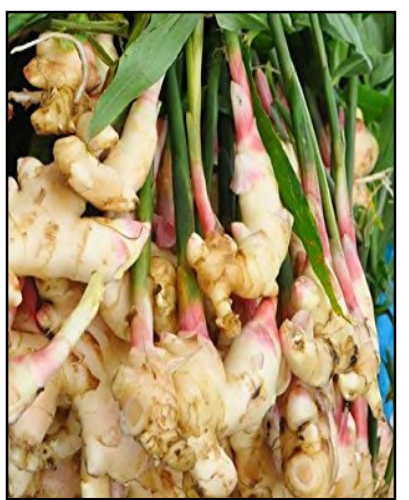

Fig. 18: Zingiber officinalis 


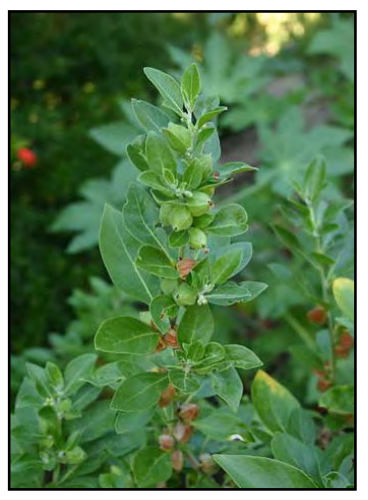

Fig. 19: Withania somnifera

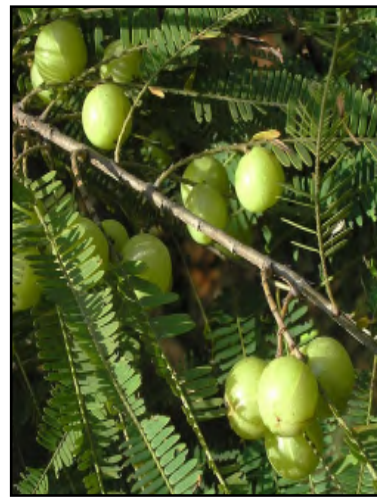

Fig. 21: Emblica officinalis

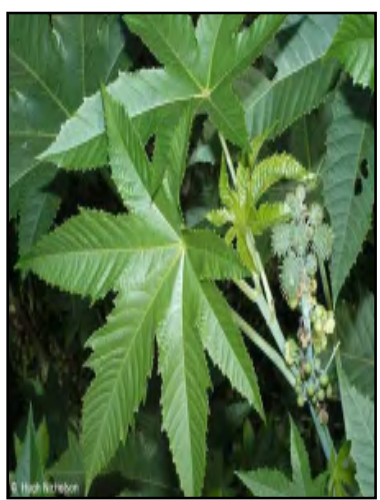

Fig. 23: Ricinus communis

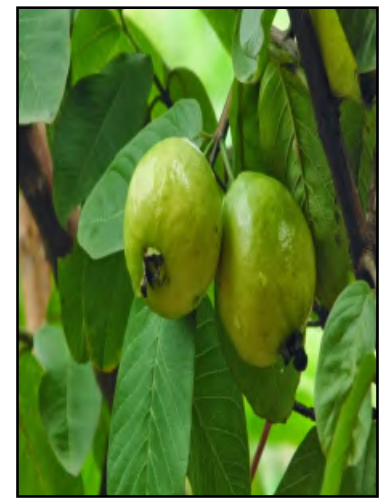

Fig. 22: Psidium guajava

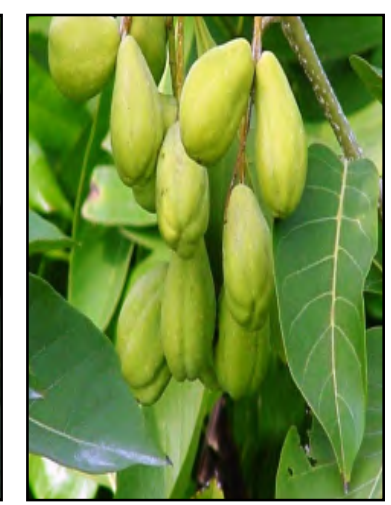

Fig. 24: Terminalia chebula

\section{Result and Discussions}

The present investigation has been carried out to survey on the Antidiabetic plants and describe the different plant part such as root, stem, leaf, bark, fruit, flower and seeds \& mode of application against diabetes. It has been observed that, these plant parts decrease the glucose level in the blood. Allium cepa possess antidiabetic potential as it was observed by Tjokroprawiro et al., (1983) conducted a comparative study in 20 cooperative diabetic patients to assess the effects of a diet including onions on diabetic symptoms as hypercholesterolemia \& serum glucose levels. Onion group had a significant decrease in blood sugar level $(4.37 \mathrm{mg} \%)$. In the treatment of diabetes the leaf juice is taken orally with honey or milk till cure. The similar observation was observed by Rajesham et al., (2012).

Gum of A. arabica is used in the diabetes. A. arabica has been proven to be a good hypolipidemic, hypoglycemic and antioxidant agent. These results are with the conformity of Hegazy et al., (2013). Leaf powder of Aegle marmelos used with cow's milk is taken orally/extracted juice mixed with a pinch of black pepper is taken orally with water daily for about one month. Neem (Azadirachta indica) extract of leaves significantly decreases the blood sugar level in the treatment of diabetes. The similar observations were observed by Biswas et al., (2002).

Oral administration of aqueous seed extract of B. juncea has a beneficial effect on diabetes. These results are with the conformity of Thirumalai et al., (2011). In the treatment of diabetes the powdered seeds mixed with lime juice are given for about 15 days to cure diabetes. Cajanus cajan, locally known as Tuar, traditionally used in the treatment of diabetes mellitus as was observed by Amalraj et al., (1998). The glucose tolerance enhancing activity of aqueous leaf and stem extract has been using in diabetes. Cooked diet of C. cajan has also shown significant hypoglycemic effect. The similar observation was observed by Esposito et al., (1991) and Panlasigui et al., (1995).

Momordica charantia is very common folklore remedy for the diabetes. These results are with the conformity of Augusti and Sheela (1996). In the treatment of diabetes oral administration of the fruit juice or seed powder causes a reduction in fasting blood glucose and improves glucose tolerance in normal and diabetic animals and in humans. Musa sapientum commonly known as Banana in English and Kela in various parts of this plant are used for different medicinal purposes including diabetes. The same observation was observed by Alarcon-Aguilara F, 1998. In the treatment of diabetes the stem extract reduces diabetes. The flowers of the plant Punica granatum a- 
re used as anti-diabetic in Unani medicine called Gulnarfarsi. The same observation was observed by Jafri et al., (2000). In the treatment of diabetes the fruits used to treat diabetes.

Indian folk medicine mentions its use for the treatment of diabetes mellitus. These results are with the conformity of Mahapatra and Pal (1985). Trigonella foenum graceum, commonly known as Methi, is a well-known hypoglycemic agent used in traditional Indian medicines. Various extracts of different parts like fibers, proteins and saponins isolated from the seeds were investigated and found to possess significant hypoglycemic activity. The Trigonella seeds significantly reduced fasting blood sugar level. In addition, it also showed significant hypolipidemic effect. The same observation was ab absolute remady Oral administration of Aloe vera might be a useful adjunct for lowering blood glucose in diabetic patients. These results are with the conformity of Modak et al., (2007). Leaves ofMangifera indica are used as an ering blood glucose in diabetic patients. These results are with the conformity of Modak et al., (2007). Leaves of Mangifera indica are used as an antidiabetic agent. Aqueous extract of Mangifera indica possess hypoglycemic activity which may be due to an intestinal reduction of the absorption of glucose observed by Aderibigbe et al., (1999).

Ocimum sanctum is commonly known as Holy basil (Tulsi). The aqueous extract of leaves of Ocimum sanctum showed a significant reduction in blood sugar level. These results are with the conformityof Rai et al., (1997). In the treatment of diabetes the leaf powder is taken orally with honey. C. papya is commonly known as papaya which belongs to the family Caricaceae. In the treatment of diabetes the Papaya are boiled and made into a paste and given with a pinch of common salt and jeera powder for six months to cure diabetes.

Zingiber officinalis is commonly known as Adark belonging to family Zingiberaceae. Extract of rhizome (decoction) if consumed regularly it shows a control in blood sugar level and the same results are supported by Uma et al., (2012). With ania somnifera leaf juice is useful for diabetes and Hibiscu rosasinesis also has anti-diabetic property. One tea spoon powder of flower mixed pepper is given once in the morning for about 10 days or more as reported by Venkat et al., (2010) and Chatterjee et al., (2015).

One spoon of leaves juice of Phyllanthus Emblica obtained from squeezed leaves is taken in the morning on an empty stomach. Fruits are also chewed and taken as much as possible, dried fruits are soaked in water and the water is taken orally with the fruit also reported by Swargiary et al., (2013) and Mahbubar et al., (2015).

Decoction made from leaf and root of Psidium guajava is consumed regularly that helps to maintain glucose level in blood as also supported by Saravanan et al., (2013) and Divya et al., (2013). Water extract of the Ricinus communis plant is given twice daily, seeds powder is taken with milk also reported by Rajeshwari et al., (2016). Rayakala et al., (2010) reported that fresh fruits of Terminalia chebula should be dried and soaked in water overnight followed by drinking the water in the morning.

\section{Conclusion}

In the present work we have concluded that people have a close relationship with the nature because; they are fully dependent for food, fruits, fodder and medicinal plants especially antidiabetic plants for their health care. Local people in this region especially old age tribal people and women heavily use these traditionally available plants for health and believe that these are easily available, less expensive and have no side effects. The present situation of traditional knowledge regarding to antidiabetic plants everywhere is an issue of deep anxiety as the traditional knowledge is gradually declining and disappearing from the country side due to deforestation, impact of tourism on natural vegetation of these region, population explosion and heavily construction and also due to climate change.

We have to make proper policies and have to implement these to conserve the forests and antidiabetic plants. Farmers and local people should be involved in the cultivation of medicinal plants at 
least on their barren and follow land. For the conservation of antidiabetic plants in the local area, we should aware the local people by seminar, workshop and short term training through government and non-government agencies at the National and International level, because we can control the diabetic effects in some extent.

During the present investigation various plant species were collected from the area. All these have medicinal value and provide comprehensive information on the medicinal plants and their indigenous uses to cure diseases in remote area of Garwal Himalaya. Based on the results it can be concluded that the area has high potential of medicinal plants species. During field visits it is also noticed that there are serious threats to herbal medicinal plants in the area due to anthropogenic activities. Therefore there is an urgent need to educate and bring awareness in the local communities, through meetings, awareness and training programs about the importance of medicinal plants and their protection.

\section{Acknowledgement}

The authors are grateful to the Dr. Gulshan Kumar Dhingra, Associate Professor, Department of Botany Govt. P.G. College Rishikesh, (Uttarakhand) for their kind support to carry out present work. The help also by the local peoples of the study area are duly acknowledged.

\section{References}

Alarcon-Aguilara, F.; Roman-Ramos, R.; Perez

Gutierrez, S.; Aguilar-Contreras, A.; Contreras-Weber, C. and Flores-Saenz, J. (1998): Study of the anti-hyperglycemic effect of plants used as antidiabetics. Journal of Ethnopharmacology. 61(2):101 -110 .

Amalraj, T. and Ignacimuthu, S. (1998): Hypoglycemic activity of Cajanus cajan (seeds) in mice. Indian Journalof Experimental Biology. 36(10):1032-1033.

Augusti, K. T. and Sheela, C. G. (1996): Antiperoxide effect of S-allylcysteine sulfoxide, an insulin secretagogue, in diabetic rats. Experientia. 52(2):115-120.
Babu, C. R. (1977): Herbaceous Flora of Dehradun, Pub. and Inf. Directorate, Council of Scientific and Industrial Research, New Delhi.

Biswas, K.; Chattopadhyay, I.; Banerjee, R. K. and Bandyopadhyay, U. (2002): Biological activities and medicinal properties of Neem (Azadirachta indica). Current Science. 82(11):1336-1345.

Chatterjee, P. and Mukherjee, A. (2015): Herbal Remedies in use in Hooghly District, West Bengal: An Ethnnomedicinal Documentation. Indian, J. Sci. Res. 10(1):1826.

Esposito, A. M.; Diaz, A.; deGracia, I.; deTello, R. and Gupta, M. P. (1991): Evaluation of traditional medicine: effects of Cajanus cajan L. and Cassia fistula L. on carbohydrate metabolism in mice. Revista Medica de Panama. 16 (1): 39-45.

European Journalof Clinival Nutrition. 44(4):301306.

Hegazy, G. A.; Alnoury, A. M. and Gad, H. G. (2013): The role of Acacia arabica extract as an antidiabetic, anti hyperlipidemic and antioxidant in streptozotocin- induced diabetic rats. Saudi Medical Journal,34 (7):727-733.

Jafri, M. A.; Aslam, M.; Javed, K. and Singh, S. (2000): Effect of Punica granatum Linn. (Flowers) on blood glucose level in normal and alloxan-induced diabetic rats. Journal of Ethnopharmacology. 70(3):309 -314 .

Kanjilal, U. N. (1928): Flora of Chakrata, Dehradun and Saharanpur. Forest Division U. (3rd ed-revised by Basant Lal). Manager of publ. Govt. of India press, India.

Khosla, P.; Gupta, D.D. and Nagpal, R. K. (1995): Effect of Trigonella foenumgraecum (Fenugreek) on blood glucose in normal and diabetic rats. Indian Journal of Physiology Pharmacology. 39(2):173174.

Mahapatra, P. K. and Pal, M. C. (1985): Prelimin- 
ary studies on glycemic effect of Syzigium cumini seeds. IRCS, Medical Science Biochemistry. 13(7):631-632.

Modak, M.; Dixit, P.; Londhe, J.; Ghaskadbi, S. and Thomas, P. A. (2007): Indian Herbs and Herbal Drugs Used for the Treatment of Diabetes; Journal of Clinical Biochemistry and Nutrition. 40(3):163-173.

Panlasigui, L. N.; Panlilio, L. M. and Madrid, J. C. (1995): Glycemic response in normal subjects to five different legumes commonly used in the Philippines. International Journal of Food Science and Nutrition. 46:155-160.

Rai, V.; Iyer, U. and Mani, U. V. (1997): Effect of Tulsi (Ocimum sanctum) leaf powder supplementation on blood sugar levels, serum lipids and tissue lipids in diabetic rats. Plant Foods for Human Nutrition. 50 (1):9.

Rajesham, V. V. and Ravindernath, A. Bikshapathi DVRN. A review on medicinal plant and herbal drugformulation used I diabetes mellitus. Indo American Journal of Pharmaceutical Research. 2(10): 12001212.

Rayakala, Venkat Kishore and Ali, Shahin Sharif (2010): Ethnobotany of plants used to cure diabetes by the people of north east India. Medicinal and aromatic plant science and biotechnology. 4(1):64-68.

Ribes, G.; Sauvaire, Y.; Da, Costa C.; Baccou, J. C. and Loubatieres-Mariani, M. M. (1986): Antidiabetic effects of subfractions from fenugreek seeds in diabetic dogs. ProcSocExpBiol Med. 182(2):159166.

Sharma, R. D.; Raghuram, T. C. and Rao, N. S. (1990): Effect of fenugreek seeds on blood glucose and serum lipids in type I diabetes.

Thirumalai, T.; Elumalai, E. K. and David, E. (2011): Hypoglycemic effect of Brassica juncea (seeds) on streptozotocin induceddiabetic male albino rat. Asian Pacific Journal of Tropical Biomedicine. 1(4):
323-325.

Tjokroprawiro, A.; Pikir, B. S.; Budhiarta, A. A.; Pranawa, Soewondo H.; Donosepoetro, M.; Budhianto, F. X.; Wibowo, J. A.; Tanuwidjaja, S. J. and Pangemanan, M. (1983): Metabolic effects of onion and green beans on diabetic patients. TheTohoku Journal of Experimental Medicine. 141: 671-676.

Uma, M. M. and Sudarsanam, D. (2012): Database on Antidiabetic indigenous plants of Tamil Nadhu, India, International Journal of Pharma Sciences and Research. 3 (2):287-293.

World Health Organization. Definition, diagnosis and classification of diabetes mellitus and its complications. World Health Organization Department of Non communicable Disease Surveillance.1999: 60 pp. Retrieved on $7 / 6 / 2007$. 